\title{
A estrutura de provisão dos serviços de saneamento básico no Brasil: uma análise comparativa do desempenho dos provedores públicos e privados
}

\author{
Juliana Souza Scriptore \\ Universidade Federal de Alfenas \\ Rudinei Toneto Júnior \\ Universidade de São Paulo
}

\begin{abstract}
O presente artigo realiza uma análise que compara o desempenho dos provedores públicos e privados de serviços de saneamento básico no Brasil. As diferenças de desempenho entre os provedores que, de acordo com a literatura, estão submetidos a diferentes incentivos foram avaliadas com base nos dados do Sistema Nacional de Informações sobre Saneamento (Snis) de 2010 a partir de uma estimativa em cross-section para uma amostra de 4.930 municípios brasileiros. Os resultados não fornecem evidências fortes de que um grupo seja superior a outro na maior parte dos indicadores. Dado que os grupos revelaram superioridade em indicadores específicos, a contribuição deste estudo é propor o desenho de uma política que considere diversas modalidades de gestão e provisão como possível solução para o desafio de universalizar os serviços no país.
\end{abstract}

Palavras-chave: análise de desempenho; indicadores de desempenho; marco regulatório; metas de universalização; privatização.

La estructura de la oferta de servicios de saneamiento en Brasil: un análisis comparativo del desempeño de los proveedores públicos y privados

En este artículo se presenta un análisis que compara el desempeño de los proveedores públicos y privados de servicios de saneamiento básico en Brasil. Las diferencias de rendimiento entre los proveedores, de acuerdo con el material están sujetos a diferentes incentivos, fueron evaluados en base a datos del Sistema Nacional de Información en Saneamiento (Snis) en 2010 desde un estimado de sección transversal para una muestra de 4.930 municipios brasileños. Los resultados no proporcionan una fuerte evidencia de que un grupo es mayor que en la mayoría de los otros indicadores. Puesto que los grupos mostraron superioridad sobre los indicadores específicos, la contribución de este trabajo es proponer el diseño de una política que tenga en cuenta las distintas formas de gestión y disposición como una posible solución al problema del servicio universal en el país.

Palabras clave: análisis de desempeño; indicadores de desempeño; los objetivos de regulación; universalización; privatización.

Artigo recebido em 27 set. 2011 e aceito em 17 ago. 2012. Os autores agradecem à Fundação de Amparo à Pesquisa do Estado de São Paulo (Fapesp) pelo financiamento para a realização do estudo e aos pareceristas pelas importantes recomendações. 
The structure of provision of basic sanitation in Brazil: a comparative analysis of the performance of public and private providers

This article provides an analysis that compares the performance of public and private enterprises of basic sanitation in Brazil. The performance differences between enterprises, according to the literature are subject to different incentives, were evaluated based on data from the Sistema Nacional de Informações do Saneamento (Snis) in 2010 from an estimated cross-section for a sample of 4.930 Brazilian municipalities. The results do not provide strong evidence that a group is higher than in most other indicators. Since the groups revealed the superiority of specific indicators, the contribution of this study is to propose the design of a policy that considers various methods of management and provision as a possible solution to the challenge of universal services in the country.

KEY WORDS: performance indicators; universalization; analysis of performance; regulatory framework; privatization.

\section{Introdução}

O setor de saneamento básico, além de prover o acesso a um direito humano elementar de todos que é a água segura, apresenta inúmeras externalidades que impactam a saúde pública, o meio ambiente, a qualidade de vida da população e a geração de renda interna nacional. Dessa forma, investir em saneamento se traduz em elemento estratégico para o desenvolvimento econômico de longo prazo do país.

A insuficiência do setor é histórica na realidade brasileira; os indicadores relativos aos serviços de água e esgoto ainda estão aquém do necessário para se alcançar as metas de universalização. Dados recentes da Pesquisa Nacional de Amostras e Domicílios (Pnad) de 2009 mostram que o número de domicílios atendidos por rede geral de abastecimento de água representou nesse ano 85,3\% do total de domicílios particulares permanentes do país. Com relação ao número de domicílios que possuem esgotamento sanitário por rede coletora de esgoto, a porcentagem do total de domicílios particulares permanentes é de 53,3\%. Ou seja, em torno de 12,1 milhões de pessoas não possuem acesso adequado a abastecimento de água e cerca de 54,4 milhões de brasileiros são desprovidos de rede coletora de esgotos sanitários e águas pluviais ou de fossa séptica (MPO, 2010).

A principal explicação para esse cenário está no descompasso existente entre o nível de investimentos efetivamente realizado e o montante necessário para eliminar o deficit de acesso. Segundo estimativas realizadas pela Associação Brasileira da Infraestrutura e Indústrias de Base (Abdib, 2010), o valor que tem sido investido anualmente, cerca de R \$ 4,7 bilhões, é inferior à quantidade necessária para atingir a universalização dos serviços: R\$ 13,5 bilhões por ano, durante 20 anos seguidos.

Outro fator que explica essa realidade é a herança do modelo de financiamento adotado no início da década de 1970, bem como sua evolução até os anos 1990. O governo 
federal implementou, em 1971, o primeiro plano voltado para eliminação do deficit de abastecimento de água e serviços de esgoto, o Plano Nacional de Saneamento, Planasa (MPO e Sepurb, 1995).

Segundo Galvão Jr. e colaboradores (2009), o Planasa constituiu marco da participação dos estados na provisão e operação da infraestrutura de saneamento no Brasil, uma vez que foram criadas as Companhias Estaduais de Saneamento Básico (Cesbs) que deveriam obter as concessões dos serviços diretamente do poder concedente, as autoridades municipais.

Assim, grande parte dos municípios brasileiros - entre aqueles que não possuíam serviços próprios de água e esgoto e tampouco dispunham de recursos para desenvolvimento, implantação, operação e manutenção desses sistemas — concedeu a prestação desses serviços às companhias estaduais então criadas (Moreira, 1998).

Contudo, com as dificuldades macroeconômicas da década de 1980 e a escassez das fontes de financiamento, as Cesbs passaram a registrar ineficiência operacional e baixa capacidade para alavancar investimentos. Ohira e Turolla (2005) afirmaram que a ênfase do Planasa na área de construção de novos sistemas (o setor de operações não era financiado pelo plano) gerou degradação dos mesmos e elevado índice de perdas de água.

A situação se agravou quando o limite de tais dificuldades levou à extinção do Planasa. De acordo com Galvão Jr. e Monteiro (2006), como consequência de tal situação, predominou um vácuo institucional no setor agravado pelo vencimento, a partir do final da década seguinte, da maioria dos contratos de concessão assinados entre os municípios e as Cesbs por períodos de 30 anos.

Na década de 1990 as políticas públicas caracterizaram-se pela ênfase na modernização e ampliação marginal da cobertura dos serviços (Ohira e Turolla, 2005). Dessa forma, pouco se avançou em termos de aumento de cobertura em decorrência de políticas desarticuladas e fragmentadas.

A aprovação da Lei no 8.987, em 1995, que autorizou a operação do setor privado na exploração de serviços públicos e, em 2004, da Lei no 11.079 fizeram com que alguns municípios optassem por privatizar a prestação de serviços de saneamento básico.

O novo ambiente institucional inaugurado com a Lei no 11.445 de 2007 trouxe perspectivas de consolidação de um marco regulatório para o saneamento básico brasileiro. Contudo, o principal desafio é a efetiva implantação das normas jurídicas enunciadas pela Lei.

As questões atuais relativas ao financiamento do setor estão associadas à retração do nível de investimentos pelas empresas públicas, regionais ou locais, que possuem baixa geração de recursos próprios, em função de problemas operacionais ou fraco estímulo à cobrança dos usuários, e apresentam limites de endividamento e restrições fiscais que impossibilitam e dificultam a captação de recursos, seja de repasses ou do mercado financeiro. Os poucos investimentos realizados por esse grupo se concentram em algumas empresas com melhor gestão e capacidade de geração de excedentes e obtenção de recursos de terceiros.

O aumento da participação da iniciativa privada no setor poderia ser visto como uma alternativa para superar as restrições de investimento enfrentadas pelas empresas públicas. 
Contudo, essa participação ainda é tímida e envolve inúmeras preocupações em relação ao oferecimento de um serviço público essencial e gerador de inúmeras externalidades, principalmente em relação à saúde pública e às taxas de mortalidade infantil. Incertezas regulatórias, jurídicas e políticas restringem o estímulo à participação do setor privado em decorrência dos elevados riscos envolvidos.

Outro ponto a ser destacado é a característica do deficit de acesso aos serviços de saneamento no país: fortemente concentrado em domicílios rurais, municípios pequenos e de baixa renda per capita, entre outras características. Esse quadro reduz a atratividade dos investimentos pelo maior montante necessário para prover os serviços em áreas mais distantes, com menor densidade populacional, menor escala e menor capacidade de pagamento (Toneto Jr. e Saiani, 2006).

Diante da complexa estrutura de provisão do setor e das características do investimento necessário percebe-se que não deverá haver uma solução única para todas as localidades e domicílios.

De qualquer modo, a superação dos problemas do setor de saneamento exige a elevação do nível de investimentos que, por sua vez, deverá requerer diversas modalidades de provisão e gestão com a participação de provedores públicos e privados, em diferentes escalas e diversas formas de articulação.

Este artigo pretende contribuir para o entendimento dessa ampla e complexa estrutura de provisão que caracteriza o setor de saneamento básico brasileiro e que, precariamente, atende suas necessidades. Pretende-se verificar o desempenho dos prestadores públicos e privados em diferentes variáveis relativas a indicadores operacionais (água e esgoto), econômico-financeiros, de investimento e qualidade. Busca-se identificar se existe diferença de performance entre esses tipos de provedores e se essa diferença pode estar relacionada aos diferentes incentivos que supostamente cada grupo possa ter: a busca de maior rentabilidade para os privados e o alcance de metas sociais para os públicos, por exemplo. A compreensão dessas diferentes motivações é de suma importância para o desenho de uma política que possa se beneficiar de todas as alternativas possíveis para superar as deficiências existentes.

A base de dados utilizada será proveniente do Sistema Nacional de Informações sobre Saneamento (Snis) para o ano de 2010. Vale destacar que esse banco de dados é autodeclaratório e, por isso, tende a apresentar uma série de imperfeições que podem gerar um problema de seleção amostral. Contudo, desde que sejam feitas as ressalvas necessárias e tomados os devidos cuidados na análise, o conjunto de informações pode ser utilizado para a obtenção dos resultados.

O artigo está dividido em quatro seções excluindo a introdução e as considerações finais. A primeira seção exibe os diversos prestadores de serviços de saneamento existentes atualmente no país. A segunda faz uma revisão da literatura acerca do desempenho e eficiência do setor público versus o privado. A terceira descreve a metodologia e formula as diferentes funções objetivo dos prestadores de serviços público e privado a fim de apresentar os sinais 
esperados dos coeficientes a serem estimados. Além disso, descreve as variáveis e a fonte dos dados. Por fim, a quarta seção aponta os principais resultados obtidos.

\section{A estrutura de provisão atual}

A estrutura de provisão do setor de saneamento é caracterizada pelo predomínio das empresas públicas regionais refletindo os diversos incentivos concedidos no Planasa para esse tipo de organização. Mas, existem outros tipos de provedores que apresentam diferentes formas de atuação geográfica e diversas naturezas jurídicas na forma de gestão.

Segundo Seroa da Motta (2006), o setor de saneamento básico apresenta uma complexa estrutura de provisão em que predominam diversos tipos de prestadores com objetivos diferentes entre si. De acordo com o autor, essa composição federativa heterogênea tem se tornado uma fonte de paralisia ao desenvolvimento do setor, uma vez que constitui foco de inúmeros conflitos de interesses.

O Snis (2010) permite identificar basicamente três grupos de prestadores, agrupados a partir de sua abrangência geográfica, que são: prestadores regionais, microrregionais e locais, cuja natureza jurídica pode ser tanto pública quanto privada. ${ }^{1}$

As empresas que atendem a mais de um município, distribuídas por estado e que geralmente atendem as regiões metropolitanas, são chamadas pelo Snis de prestadores regionais. ${ }^{2}$ De um total de 27 empresas desse tipo, a maioria (22) é sociedade de economia mista com predominância de capital e gestão pública. A Companhia de Saneamento Básico do Estado de São Paulo (Sabesp) e a Companhia de Saneamento de Minas Gerais (Copasa) são exemplos de empresas desse grupo.

As empresas locais fornecem serviços de saneamento básico exclusivamente a um único município e podem ser públicas ou privadas. Dos 936 prestadores locais existentes, apenas 42 são empresas privadas e o restante são autarquias (394), administrações públicas diretas (478), organizações sociais (3), sociedades de economia mista com administração pública (10) e empresas públicas (3).

Os prestadores microrregionais atendem a uma pequena quantidade de municípios com proximidade geográfica: dos sete prestadores existentes desse tipo, três são empresa privada e quatro são autarquias. A tabela 1 resume essas informações.

\footnotetext{
${ }^{1}$ Nesse trabalho convencionou-se que as empresas do grupo das privadas são aquelas classificadas pelo Snis como empresa privada e aquelas do grupo das públicas contêm empresas que exibem as seguintes naturezas jurídicas: sociedade de economia mista com administração pública, empresa pública, autarquia, administração pública direta. ${ }^{2}$ Correspondem às extintas Companhias Estaduais de Saneamento Básico (Cesbs), da época do Planasa.
} 
Tabela 1

Agrupamento dos prestadores por abrangência regional e natureza jurídica

\begin{tabular}{|lcccc|}
\hline Natureza jurídica & Regional & Microrregional & Local & Total \\
\hline Administração pública direta & 0 & 0 & 478 & 478 \\
Autarquia & 3 & 2 & 394 & 399 \\
Empresa pública & 1 & 0 & 3 & 4 \\
Sociedade economia mista - Administração pública & 22 & 0 & 10 & 32 \\
Empresa privada & 1 & 3 & 48 & 52 \\
Organização social & 0 & 0 & 3 & 3 \\
Total & 27 & 5 & 936 & 968 \\
\hline
\end{tabular}

Fonte: Elaboração própria baseada em Snis (2010).

A concessão de serviço público é o instrumento através do qual o Estado atribui o exercício de um serviço público a alguém que aceita prestá-lo em nome próprio, por sua conta e risco, nas condições fixadas e alteráveis unilateralmente pelo poder público, mas sob garantia contratual de um equilíbrio econômico-financeiro, remunerando-se pela própria exploração dos serviços, em geral e basicamente mediante tarifas cobradas dos usuários dos serviços (Bandeira de Mello, 2008). Portanto, uma característica bem definida da concessão comum é a obtenção de receitas autossuficientes pelo concessionário.

Quando o projeto de infraestrutura ou a prestação de serviço público não for atrativo para a iniciativa privada, faz-se necessária a complementação de recursos fiscais, ou seja, deve existir contraprestação pecuniária do parceiro público ao privado. Nessas circunstâncias são estabelecidos os contratos de parcerias público-privadas. A Lei no 11.079 de 2004 define duas modalidades desse tipo contratual: patrocinada ou administrativa.

A maior parte das concessões realizadas no setor de saneamento básico é do tipo concessão plena, ou seja, o setor privado tem responsabilidade geral sobre a operação, manutenção, administração e investimentos de capital para a expansão dos serviços (água e esgoto). Além disso, é remunerado diretamente pelos consumidores.

Na década atual, muitas incertezas regulatórias estiveram presentes na definição de políticas de saneamento, o que impossibilitou o avanço maior dessas empresas no setor. Com a promulgação da Lei no 11.445 do Saneamento, o esperado marco regulatório do setor, existe perspectiva de se criar um ambiente propício (mesmo que futuramente, até que seja de fato consolidado) de realização dos investimentos necessários à universalização.

\section{Desempenho e eficiência: público versus privado}

A provisão dos serviços de saneamento básico assume diferentes formas nos diversos países, passando por modelos totalmente baseados em provedores públicos até provisão totalmente 
privada. As características do setor que podem resultar em tendência ao monopólio natural e as profundas externalidades que gera requerem a presença do setor público seja na provisão seja na forma de regulação. As sérias deficiências existentes em vários países na provisão de serviços, a baixa cobertura, os elevados índices de ineficiência e os grandes montantes de investimento necessários têm colocado uma pressão cada vez maior para a participação do setor privado em diversos países. Pelas fortes características sociais do setor, diversos estudos começaram a avaliar a questão do desempenho dos provedores públicos e privados. As comparações referem-se a vários aspectos: custos de provisão, cobertura do acesso, qualidade dos serviços, entre outros.

Deve-se destacar que a possibilidade de mensuração e monitoramento do desempenho dos prestadores de serviços regulados é uma obrigação pela própria necessidade de se garantir a continuidade dos serviços, o acompanhamento do cumprimento das metas contratuais, a avaliação do desempenho financeiro e seu equilíbrio, entre outras questões previstas em contratos, seja para provedores públicos ou privados.

Entre os trabalhos que buscam comparar o desempenho dos provedores públicos e privados no setor de saneamento básico, deve-se destacar o de Estache e Rossi (2002), um dos primeiros realizados. Esse trabalho utiliza o método de fronteira estocástica e estima uma função de custo para uma amostra de 50 empresas regionais de água de 29 países da região da Ásia e Pacífico, tendo 22 delas alguma forma de participação do setor privado. Os resultados encontrados pelos autores mostram que a eficiência não é significativamente diferente entre os prestadores de serviços públicos e privados.

Seroa da Motta e Moreira (2004) analisaram o setor de saneamento brasileiro usando o método DEA (Data Envelopment Analysis), considerando todos os operadores do território nacional. A amostra foi composta de 104 operadores (73 locais, 20 regionais e 11 privados). Os autores apontam que os efeitos de catch up, ou seja, movimentos em direção à fronteira tecnológica, são mais importantes que o crescimento da produtividade total de fatores, no período de 1997 a 2002. A introdução de gestão privada foi um fator relevante de contribuição para movimentos em direção à fronteira. O estudo também avalia que os operadores regionais se beneficiam de economias de escala, mas que operam com níveis mais baixos de produtividade e não foram capazes de ganhar produtividade no mesmo ritmo dos operadores locais no período analisado.

Ao utilizar o método (paramétrico) de fronteira de produção estocástica para 148 empresas brasileiras (sendo 135 públicas e 13 privadas), Faria, Moreira e Souza (2005) mostram que os prestadores de serviços privados são apenas marginalmente mais eficientes que os públicos.

Bel, Fageda e Warner (2010), ao avaliar os resultados de um conjunto de estudos econométricos por meio da análise de metarregressão, não encontraram fortes evidências de que a produção privada traga menores custos para o setor, ainda que a média da estatística $t$ para esses diferentes estudos tenha sido negativa.

Merece destaque o apontamento dos autores de que futuras análises empíricas devam levar em consideração as características dos serviços (tais como o potencial de melhoras 
tecnológicas e os custos irrecuperáveis), os custos de transação, o monitoramento e especificação dos contratos e outras características ligadas ao ambiente político, empresarial e de mercado (concorrência).

O trabalho de Kirkpatrick, Parker e Zhang (2004), baseado em indicadores estatísticos e no DEA, confirma que a privatização pode levar a ganhos de desempenho. No entanto, apesar de o coeficiente de propriedade ser negativo pelo método de fronteira estocástica para função custo (indicando que a propriedade privada pode implicar menores custos), o mesmo não foi estatisticamente significante.

Por outro lado, Estache e Kouassi (2002), ao utilizarem uma amostra de 22 empresas africanas de distribuição de água para o período de 1995 a 1997, estimaram uma função de produção a partir de dados em painel não balanceado e, por meio de uma modelagem Tobit, concluíram que o fato de a empresa ser de propriedade privada está associado a um baixo nível do score de ineficiência. ${ }^{3}$

Além desses estudos, outras importantes hipóteses são testadas em relação à atuação dos operadores privados. Galiani, Gertler e Schargrodsky (2005) encontraram, na Argentina, baixos (e significativos) níveis de mortalidade infantil em localidades que privatizaram seus serviços em relação às cidades que mantiveram a provisão estatal dos mesmos. Entre outros fatores, esse resultado, segundo os autores, pode estar relacionado a um maior nível de qualidade na água distribuída que, por sua vez, evita a proliferação de vetores que causam doenças infectocontagiosas, principal causa da mortalidade infantil tanto no Brasil como em inúmeros países da América Latina.

De posse da análise de tais resultados, o principal objetivo do trabalho é comparar o desempenho de empresas públicas e privadas na provisão de serviços de saneamento básico no país. Tenta-se verificar se os incentivos com os quais cada grupo se defronta determinam diferenças em suas atuações, ou seja, se a busca de maior rentabilidade pelas empresas privada reflete em menor custo, maior capacidade de investimento, mas, eventualmente, pior qualidade e menores indicadores de atendimento. Ou se as empresas públicas possuem menor produtividade (maior pressão para gerar emprego), menores tarifas, mas maior atendimento das demandas sociais. Tais expectativas podem ser justificadas do ponto de vista teórico.

Segundo Parlatore (2000), empresas públicas geralmente apresentam um excessivo aumento do quadro de pessoal buscando atender pressões políticas. Ou ainda, existe uma forte preocupação com sua natureza social, desconsiderando a necessidade de cobrança de serviços, ganhos de eficiência e mesmo necessidade de apresentar desempenho financeiro adequado.

Cabral, Lazzarini e Azevedo (2007) também argumentam que empresas públicas apresentam uma política de substituição de trabalhadores pouco ágil, pelo fato de estarem submetidas a vários procedimentos burocráticos que envolvem processos de contratação e limitações

\footnotetext{
${ }^{3}$ Outros trabalhos voltados à discussão de questões relacionadas à eficiência e desempenho entre empresas públicas e privadas são Crain e Zardkoohi (1978), Feigenbaum e Teeples (1983) e Estache e Rossi (1999).
} 
fiscais. Segundo eles, os contratos de trabalho do setor público são mais rígidos e os trabalhadores respondem menos aos objetivos de desempenho.

De acordo com Moreira (1998), a ineficiência operacional de empresas do setor público também é refletida nos altos custos com pessoal, pelo fato de possuírem tecnologia defasada, dificuldades de manutenção técnica do sistema e trabalhadores menos produtivos e motivados. Ou seja, indicadores de produtividade e de desempenho financeiro das públicas tendem a ser menores.

Por outro lado, a atuação única do setor privado não é solução para tais impasses. Um dos motivos se baseia nas características econômicas do setor de saneamento (caso típico de monopólio natural). Além desse argumento, Toneto Jr. e Saiani (2006) elencaram mais um fator que dificulta o aumento do índice de atendimento de serviços de saneamento pelos prestadores privados: o deficit de acesso é concentrado nas regiões mais pobres, na zona rural, nos municípios de menor porte, naqueles que apresentam menor taxa de urbanização e menor renda per capita e nos domicílios de baixa renda. Dessa forma, essas características implicam maiores custos de investimento para esses prestadores e refletem também maiores riscos; consequentemente, ocorre um afastamento da iniciativa privada desses municípios (os que mais necessitam de investimentos).

Com relação à aplicação de tarifas desses dois grupos de operadores, Fernandois (2009) evidencia que a vantagem de as empresas privadas imporem tarifas que atendam a seus interesses, sem que estejam submetidas a pressões externas que as afetem, não garante a obtenção de tarifa justa. Ao contrário, tais empresas determinam um nível de tarifa abaixo daquele que remunera adequadamente capital e mão de obra, incompatível com a prestação eficiente dos serviços.

O argumento da cobrança de menores tarifas pelos operadores públicos pode se dar, de acordo com Toneto Jr. e Saiani (2006), tanto por facilidades tributárias dessas empresas como pode refletir a maior dificuldade política de se cobrar dos consumidores pela proximidade entre eleitor e gestor do serviço.

Quanto à qualidade dos serviços, Cabral, Lazzarini e Azevedo (2007) defendem que, sem um agente fiscalizador, o alto poder de incentivo do setor privado para reduzir custos pode fazê-lo negligenciar outras dimensões de desempenho, tais como a qualidade.

Esse conjunto de trabalhos mostra que não existe um consenso sobre a maior eficiência do setor privado em relação ao setor público em qualquer metodologia que se considere. A literatura destaca que pode haver diferentes motivações entre os tipos de provedores e os distintos objetivos que devem ser alcançados no setor. Assim, provedores públicos podem alcançar de forma mais adequada determinados objetivos de natureza social, enquanto os privados podem ser mais adequados para alcançar eficiência técnica ou financeira. Dessa forma, modelos híbridos podem se fazer necessários para o alcance de objetivos sociais respeitando critérios de eficiência. Inserido nesse debate, a contribuição do presente estudo é verificar se os diferentes tipos de provedores apresentam divergências nos indicadores de desempenho de forma a confirmar ou contrariar os incentivos (expressos por suas respectivas funções objetivo) aos quais espera-se que estejam submetidos. 


\section{Metodologia}

A base de dados utilizada no trabalho é a do Snis, para o ano de 2010, que fornece uma série de informações sobre o setor, seja por provedor seja por município. Os indicadores do Snis selecionados estão distribuídos nos seguintes grupos: Atendimento (Atendimento Total de Água e Atendimento Total de Esgoto), Operacionais (Índice de Perdas na Distribuição, Índice de Perdas no Faturamento), Econômicos, Financeiros e Administrativos (Tarifa Média Praticada, Despesa Total com os Serviços por $\mathrm{m}^{3}$ faturado, Empregados Próprios por ligação de água e esgoto e Índice de Desempenho Financeiro), Investimento (Investimento total por ligação de água e esgoto, Investimento Total por habitante, Investimentos realizados com Recursos Onerosos, Investimentos realizados com Recursos não Onerosos e Investimentos realizados com Recursos Próprios) e um Indicador de Qualidade.

O Snis recebe de forma voluntária as informações dos prestadores de serviços de saneamento básico. Portanto, os municípios que apresentam melhores resultados nos índices de atendimento sanitário tendem a se comprometer mais com a divulgação das informações. Além disso, o banco de dados apresenta inúmeras imperfeições, tais como desconhecimento das perguntas e erros de preenchimento não captados pelos testes de consistência aplicados pelo Snis.

Apesar da significativa representatividade do Snis, a amostra varia ao longo do tempo, pois, a cada ano, novos prestadores convidados passam a divulgar suas informações e pode acontecer de aqueles que informavam regularmente todos os anos deixarem de informar por qualquer motivo, já que não existe uma lei que os obrigue a essa prática. Contudo, apesar dessas limitações, o Snis é o maior e mais importante banco de dados do setor e conta com uma expressiva fonte de informações (sua série histórica apresenta 15 anos de dados divulgados).

Para alcançar o objetivo de análise comparativa de desempenho desenvolveram-se análises econométricas para avaliar como a estrutura de governança (empresa privada, local pública e regional) afeta o desempenho das empresas de saneamento no Brasil. Os dados dessa análise são de corte transversal (cross-section), que se referem a uma amostra de 4.930 municípios brasileiros tomada em um determinado ponto do tempo, o ano de 2010.

O método de estimação utilizado é o de Mínimos Quadrados Ordinários (MQO), que estabelece como variável dependente os diferentes indicadores de desempenho dos prestadores de serviços de saneamento, explicados pelas variáveis relativas às características municipais e ao tipo de prestador atuante no município, de acordo com a seguinte forma funcional, linear nos parâmetros, definida a seguir:

$$
Y=\alpha+\beta X_{1}+\gamma X_{2}+\varepsilon
$$

$Y$ : Vetor de características operacionais e de atendimento, características econômicas, financeiras e administrativas e características de investimento e qualidade.

$X_{1}$ : Vetor de características municipais (renda per capita, taxa de urbanização, tamanho da população e região geográfica de localização do município, por exemplo). 
$X_{2}$ : Vetor de variáveis dummies dos diferentes tipos de prestadores (empresa privada, local pública e regional).

Dessa forma, controlando-se por características municipais, pode-se observar se a literatura está condizente com as funções e atribuições estabelecidas para cada tipo de prestador e, dessa forma, analisar em qual campo de atuação um ou outro prestador é mais eficaz.

Entre as variáveis utilizadas para a estimação dos índices de desempenho, existem dois grupos de variáveis binárias: um dos grupos refere-se à região de localização geográfica do município. Há, no modelo, cinco variáveis desse tipo: Sul, Norte, Nordeste, Centro-Oeste e Sudeste. Essa última foi utilizada como grupo base nos testes pelo fato de que geralmente essa região apresenta os melhores resultados para os diversos indicadores.

O outro grupo refere-se ao tipo de prestador de serviço que atua no município em questão. As empresas regionais e microrregionais, aquelas que atendem a mais de um município, foram agregadas no grupo das não locais e aquelas que atendem a um, e somente um, município, constituem o grupo das locais.

De ambos os grupos foram selecionados todos os prestadores classificados pelo Snis como empresa privada ${ }^{4}$ e, assim, criou-se a variável binária privada_total, que assume valor igual a um, se o município tiver seus serviços de saneamento fornecidos por uma empresa privada, e zero, se a empresa for pública. Do grupo das locais foram retirados os prestadores de serviços locais privados e também criada outra variável binária chamada local_pública. Ao se introduzir na estimação essas duas variáveis, o grupo base se constitui das não locais (regionais e microrregionais) públicas, ${ }^{5}$ que são os prestadores que atendem a maioria da população brasileira, cuja natureza jurídica, em geral, diz respeito à sociedade de economia mista com administração pública.

As variáveis apresentadas acima foram dispostas, em grande parte das estimações, da seguinte maneira:

$$
Y=\alpha+(\ldots)+\beta_{4} n o+\beta_{5} n e+\beta_{6} s u+\beta_{7} c o+\gamma_{1} \text { privada_total }+\gamma_{2} \text { local_pública }
$$

Nessa composição, pretende-se fazer a seguinte pergunta, ao analisar, por exemplo, o coeficiente: empresas de gestão privada, quando comparadas com empresas que atendem a mais de um município e possuem gestão pública, são melhores/piores que essas empresas em quais indicadores de desempenho, mantendo todos os outros fatores constantes?

Além das variáveis binárias, as outras variáveis explicativas, de caráter quantitativo, são relacionadas às características municipais. A primeira delas é a "renda", que se refere à renda per capita municipal, calculada pela relação entre o Produto Interno Bruto (PIB) de cada

\footnotetext{
${ }^{4}$ Entidade que possui capital predominante ou integralmente privado, administrada exclusivamente por particulares (SNIS, 2010).

${ }^{5}$ Adotou-se, ao longo do texto, a convenção de se referir a esse grupo, as não locais públicas, de apenas regionais públicas.
} 
município e a população total do mesmo. A variável "urb" é a taxa de urbanização municipal, calculada como a razão entre a população urbana do município dividida por sua população total. A variável "log_pop" foi obtida através do cálculo do logaritmo da população total do município. Essa transformação foi feita para linearizar o modelo e evitar possíveis correlações amostrais entre as variáveis. Seguem as estatísticas descritivas na tabela 2.

Tabela 2

Estatísticas descritivas das variáveis explicativas

\begin{tabular}{|lccccc|}
\hline Variável & Obs. & Média & Desvio padrão & Mínimo & Máximo \\
\hline urb & 4.930 & 0,652 & 0,216 & 0,042 & 1 \\
renda & 4.926 & 7,340 & 9,855 & 0,758 & 279,112 \\
log_pop & 4.930 & 9,479 & 1,160 & 6,691 & 16,236 \\
NO & 4.930 & 0,069 & 0,254 & 0 & 1 \\
NE & 4.930 & 0,320 & 0,467 & 0 & 1 \\
SE & 4.930 & 0,306 & 0,461 & 0 & 1 \\
SU & 4.930 & 0,220 & 0,414 & 0 & 1 \\
CO & 4.930 & 0,085 & 0,278 & 0 & 1 \\
privada_total & 4.930 & 0,038 & 0,191 & 0 & 1 \\
local_pública & 4.930 & 0,180 & 0,384 & 0 & 1 \\
local_privada & 4.930 & 0,010 & 0,098 & 0 & 1 \\
\hline
\end{tabular}

Fonte: Elaboração própria baseada em Snis (2010).

Quanto às variáveis dependentes, a maior parte delas é de indicadores calculados pelo Snis, mas outras foram calculadas com informações primárias fornecidas pelo mesmo. Segue explicação da composição de cada variável. Para os indicadores operacionais de água, têm-se as seguintes variáveis:

、Ind_atendimento_água $=\frac{\text { População_total_atendida_água }}{\text { Pop_total_municípios_atendidos_água }}$

จInd_perdas_distribuição $=\frac{\text { Volume_água }- \text { Volume_água_consumido }}{\text { Volume_água }}$

$\checkmark$ Ind_perdas_faturamento $=\frac{\text { Volume_água }- \text { Volume_água_faturado }}{\text { Volume_água }}$

Em relação ao grupo dos indicadores operacionais de esgoto, foram utilizadas as variáveis a seguir: 
vInd_atendimento_esgoto $=\frac{\text { Volume_total_atendida_esgoto }}{\text { Pop_total_municípios_atendido_água }}$

Os indicadores econômicos, financeiros e administrativos apresentam as seguintes variáveis definidas a seguir:

$\checkmark$ Tarifa_média_praticada $=\frac{\text { Receita_Operacional_Direta }(A+E)}{\text { Volume_Total_Faturado }(A+E)}$

$\checkmark$ Despesa_Total_Serviços $=\frac{\text { Despesas_totais_seviços }}{\text { Volume_Total_Faturado }(A+E)}$

$\checkmark$ Empregados_próprios_ligações $(A+E)=\frac{\text { Total_empregados_próprios }}{\text { Total_ligações_ativas }(A+E)}$

、Indicador_desempenho_financeiro $=\frac{\text { Receita_Operacional_Direta }}{\text { Despesas_totais_serviços }}$

O grupo dos indicadores de investimento é formado pelas seguintes variáveis:

$\checkmark$ Investimento_ligação $=\frac{\text { Investimentos_totais }}{\text { Ligações_totais }(A+E)}$

$\checkmark$ Investimento_habitante $=\frac{\text { Investimento_total }}{\text { População_total_municípios }}$

$\checkmark$ Investimento_rec_onerosos $=\frac{\text { Inv_com_recursos_onerosos }}{\text { Investimento_total }}$

$\checkmark$ Investimento_rec_não_onerosos $=\frac{\text { Inv_com_recursos_não_onerosos }}{\text { Investimento_total }}$

$\checkmark$ Investimento_rec_próprios $=\frac{\text { Inv_com_recursos_próprios }}{\text { Investimento_total }}$

Por fim, o indicador de qualidade foi obtido da seguinte maneira: para cada um dos seguintes indicadores de qualidade: duração média dos serviços executados (I1), duração média das paralisações (I2), incidência de análises de cloro residual fora do padrão (I3), incidência de análises de turbidez fora do padrão (I4), incidência de análises de coliformes fecais fora do padrão (I5), aplicou-se a fórmula: 
$I_{j}=\frac{x_{i}-x_{\min }}{X_{M A X}-X_{M I N}}, j=1 \ldots 5 \rightarrow$ Ind_qual $=\frac{I^{\prime} 1+I^{\prime} 2+I^{\prime} 3+I^{\prime} 4+I^{\prime} 5}{5}$

$\mathrm{O}$ valor do denominador refere-se à diferença entre o pior e o melhor valor, entre todos os valores exibidos pelo indicador $\mathrm{j}$ em questão. $\mathrm{O}$ numerador refere-se ao cálculo de cada valor individual deduzido do valor mínimo do intervalo. Logo, quanto mais próximo o valor individual estiver do melhor valor do intervalo, irá se obter um indicador próximo a 1: $x_{\max }-x_{\min }=X_{M A X}-X_{M I N}$. Para chegar ao indicador final de qualidade calcula-se a média para cada indicador transformado. Quanto maior esse indicador, pior será o resultado em termos de qualidade.

Os resultados esperados para as estimativas das variáveis descritas acima, comparandose o setor público e privado, encontram-se resumidos no quadro seguinte.

Quadro

As funções objetivo e sinais esperados dos coeficientes das variáveis dependentes

\begin{tabular}{|c|c|c|c|}
\hline & Indicadores & $\begin{array}{c}\text { Privada } \\
\text { (sinal esperado } \\
\text { do coeficiente) }\end{array}$ & $\begin{array}{c}\text { Pública } \\
\text { (sinal esperado } \\
\text { do coeficiente) }\end{array}$ \\
\hline \multirow[t]{4}{*}{ Operacionais } & Índice Perdas Faturamento [\%] & - & + \\
\hline & Índice Perdas Distribuição [\%] & - & + \\
\hline & Índice Atendimento Total Ag. [\%] & - & + \\
\hline & Índice Atendimento Total Esg. [\%] & - & + \\
\hline \multirow{4}{*}{$\begin{array}{l}\text { Produtividade, } \\
\text { Econômicos e } \\
\text { administrativos }\end{array}$} & Empregados próprios/ mil ligaç̃̃es (A+E) [empreg./mil lig.] & - & + \\
\hline & Despesa total com serviço/m $/ \mathrm{m}^{3}$ faturado $\left[\mathrm{R} \$ / \mathrm{m}^{3}\right]$ & - & + \\
\hline & Tarifa média praticada $\left[\mathrm{R} \$ / \mathrm{m}^{3}\right]$ & + & - \\
\hline & Indicador de desempenho financeiro [\%] & + & - \\
\hline \multirow[t]{5}{*}{ Investimento } & Investimento total/população dos municípios & + & - \\
\hline & Investimento total/número de ligações $(A+E)$ & + & - \\
\hline & Recursos onerosos/investimento total (\%) & + & - \\
\hline & Recursos não onerosos/investimento total (\%) & - & + \\
\hline & Recursos próprios/investimento total (\%) & + & - \\
\hline Qualidade & Indicador de qualidade & + & - \\
\hline
\end{tabular}

Fonte: Elaboração própria baseada em Snis (2010).

Tal como foi justificado pelo referencial teórico, é esperado que empresas públicas apresentem maiores índices relativos a perdas de distribuição e perdas de faturamento. Portanto, os sinais esperados para esses dois índices são positivos, para o grupo das públicas, e negativos, 
para o grupo das privadas. Em relação ao indicador de acesso refletido no índice de atendimento total de água e esgoto, espera-se um melhor desempenho dos prestadores públicos atribuído a uma possível função social dos mesmos.

$\mathrm{O}$ indicador de produtividade relativo ao número de empregados próprios por mil ligações de água e esgoto revela que quanto menor seu resultado menos inchado se encontrará o quadro de funcionários da empresa. Dessa forma, as empresas privadas se destacariam nesse indicador apresentando parâmetro negativo.

De acordo com os argumentos teóricos anteriores, maiores tarifas são típicas das empresas privadas principalmente se não estão submetidas a marcos regulatórios. Por outro lado, espera-se um baixo nível de tarifas das públicas, tanto pela função social que executam quanto pelas facilidades tributárias que essas podem conceder.

No mesmo sentido, pode existir uma tendência de que as empresas privadas registrem uma menor despesa com os serviços totais por $\mathrm{m}^{3}$ faturado e um maior indicador de desempenho financeiro, que mostra o percentual da Receita Operacional Direta em relação à Despesa Total. Ou seja, espera-se que o grupo das empresas privadas apresente um sinal positivo para essa variável. Em relação ao indicador de qualidade, espera-se que as empresas privadas sacrifiquem a qualidade dos serviços a fim de obter menores custos. De acordo com a construção do indicador (quanto menor, melhor), espera-se sinal positivo para o seu coeficiente.

Por fim, a tendência de que as privadas são as que mais efetivamente investem, na mesma linha de argumentação de que podem tomar maiores recursos de empréstimos e se endividar mais, se reflete no indicador de investimento total pelo número de ligações de água e esgoto e investimento total por habitante. Isso indica sinais positivos dos coeficientes.

Além disso, a parcela de investimento total realizado com recursos onerosos tende a ser maior para esse grupo, pois exibe maior capacidade de se endividar via obtenção de financiamentos. A parcela de investimento total realizado com recursos próprios também tende a ser positiva, uma vez que essas empresas geram receita num montante maior que as despesas, por meio de tarifas maiores. E a parcela de investimento total realizado com recursos não onerosos (a fundo perdido) é nula ou bem pequena, já que não recebem esse tipo de recursos. Logo, com exceção desse último índice, em que se espera sinal negativo, para todos existe a expectativa de se obter sinal positivo para o grupo das empresas privadas.

Antes do próximo passo desse estudo, testar os sinais esperados das funções-objetivo de cada grupo, seguem na tabela 3 as estatísticas descritivas, para todos os valores observados da amostra, das variáveis dependentes listadas anteriormente.

A tabela 3 destaca alguns aspectos importantes do setor. O primeiro aspecto a ser considerado é em relação ao atendimento. Na média, observa-se um baixo grau de atendimento de água e esgoto, fato que reflete o elevado deficit de serviços no país. Os dados mostram que o atendimento das públicas locais, na média, supera o das privadas e das regionais, que, por sua vez, tendem a apresentar os piores indicadores. 
Tabela 3

Estatísticas descritivas das variáveis dependentes

\begin{tabular}{|c|c|c|c|c|c|c|}
\hline \multirow[b]{2}{*}{ Variável } & \multicolumn{2}{|c|}{ Privada } & \multicolumn{2}{|c|}{ Local_pública } & \multicolumn{2}{|c|}{ Regional_pública } \\
\hline & Média & $\begin{array}{l}\text { Desvio } \\
\text { Padrão }\end{array}$ & Média & $\begin{array}{l}\text { Desvio } \\
\text { Padrão }\end{array}$ & Média & $\begin{array}{l}\text { Desvio } \\
\text { Padrão }\end{array}$ \\
\hline Índice atendimento total de água (\%) & 68,265 & 17,942 & 80,045 & 20,242 & 61,135 & 23,449 \\
\hline Índice perdas na distribuição (\%) & 31,525 & 14,047 & 25,043 & 18,900 & 35,048 & 18,573 \\
\hline Índice perdas no faturamento (\%) & 22,111 & 14,711 & 32,508 & 28,403 & 29,941 & 21,067 \\
\hline $\begin{array}{l}\text { Índice atendimento total de esgoto referido aos } \\
\text { municípios atendidos com água (\%) }\end{array}$ & 52,793 & 28,821 & 65,861 & 30,530 & 45,557 & 30,343 \\
\hline Tarifa média praticada $\left(\mathrm{R} \$ / \mathrm{m}^{3}\right)$ & 2,162 & 0,441 & 1,073 & 0,735 & 2,400 & 1,404 \\
\hline Despesa total com os serviços por $\mathrm{m}^{3}$ faturado $\left(\mathrm{R} \$ / \mathrm{m}^{3}\right)$ & 2,680 & 1,287 & 1,057 & 0,673 & 3,555 & 12,303 \\
\hline $\begin{array}{l}\text { Empregados próprios por mil ligações de água e esgoto } \\
\text { (empregados/ligação) }\end{array}$ & 4,352 & 2,222 & 3,746 & 2,958 & 2,650 & 4,570 \\
\hline Índice de desempenho financeiro (\%) & 102,880 & 85,058 & 96,390 & 55,592 & 95,437 & 78,788 \\
\hline $\begin{array}{l}\text { Investimento total por ligações de água e esgoto } \\
(\mathrm{R} \$ / \text { ligação) }\end{array}$ & 64,060 & 92,577 & 45,092 & 105,885 & 81,475 & 236,703 \\
\hline Investimento total por habitante ( $\mathrm{R} \$$ /habitante) & 18,757 & 32,922 & 15,255 & 30,712 & 23,237 & 75,474 \\
\hline Índice de qualidade (\%) & 0,0052 & 0,006 & 0,029 & 0,059 & 0,013 & 0,023 \\
\hline
\end{tabular}

Fonte: Elaboração própria baseada no Snis (2010).

Outro aspecto a ser destacado é a profunda ineficiência do setor, o que pode ser visto pelas elevadas perdas de distribuição de água na rede e no faturamento. O simples aumento da eficiência já contribuiria para ampliar a provisão dos serviços. Nesses itens observa-se que as privadas possuem, na média, as menores perdas e as regionais, as maiores. As tarifas das privadas tendem a ser maiores que as das públicas locais e menores que as regionais. Além disso, o desempenho financeiro das privadas, na média, é melhor.

Esses resultados não permitem que se façam afirmações sobre o desempenho relativo dos diferentes grupos. Esses indicadores podem estar refletindo outros fatores, que não o tipo de provedor, como características municipais. Assim, na próxima seção, pretende-se verificar se os indicadores de desempenho decorrem de diferenças entre os tipos de provedores ou de características municipais.

\section{Resultados}

O primeiro grupo de resultados apresentados contém os indicadores operacionais e de atendimento de água e esgoto cujos valores são identificados na tabela 4. 
Tabela 4

Estimação dos indicadores operacionais e de atendimento de água e esgoto

\begin{tabular}{|c|c|c|c|c|}
\hline $\begin{array}{l}\mathrm{X}_{\mathrm{i}}=\text { Variáveis } \\
\text { explicativas }\end{array}$ & $\begin{array}{c}Y_{1}=\text { Índice } \\
\text { atendimento total de } \\
\text { água (\%) }\end{array}$ & $\begin{array}{c}Y_{2}=\text { Índice perdas na } \\
\text { distribuição (\%) }\end{array}$ & $\begin{array}{c}Y_{3}=\text { Índice perdas no } \\
\text { faturamento }(\%)\end{array}$ & $\begin{array}{c}\mathrm{Y}_{4}=\text { Índice } \\
\text { atendimento total de } \\
\text { esgoto }(\%)\end{array}$ \\
\hline & \multicolumn{4}{|c|}{ Coeficientes } \\
\hline \multirow{3}{*}{ renda } & 1 & 2 & 3 & 4 \\
\hline & 0,051 & 0,010 & 0,045 & 0,046 \\
\hline & $(0,033)$ & $(0,023)$ & $(0,031)$ & $(0,043)$ \\
\hline \multirow{2}{*}{ urb } & $79,327 *$ & $5,316^{*}$ & $-1,202$ & $70,883^{*}$ \\
\hline & $(1,237)$ & $(1,444)$ & $(1,959)$ & $(3,003)$ \\
\hline \multirow{2}{*}{ log_pop } & $-1,687^{*}$ & $2,531^{*}$ & $2,425^{*}$ & $-3,268^{*}$ \\
\hline & $(0,178)$ & $(0,227)$ & $(0,293)$ & $(0,455)$ \\
\hline \multirow{2}{*}{ NO } & $-18,118^{*}$ & $18,555^{*}$ & $24,588^{*}$ & $-47,724^{*}$ \\
\hline & $(1,205)$ & $(1,364)$ & $(1,706)$ & $(3,248)$ \\
\hline \multirow{2}{*}{ NE } & $-3,005^{*}$ & $14,009 *$ & $16,974^{*}$ & $-34,477^{*}$ \\
\hline & $(0,548)$ & $(0,689)$ & $(0,885)$ & $(1,614)$ \\
\hline \multirow{2}{*}{ SU } & $3,085^{*}$ & $3,339 *$ & $1,472^{* * *}$ & $-30,303^{*}$ \\
\hline & $(0,531)$ & $(0,540)$ & $(0,764)$ & $(1,648)$ \\
\hline \multirow{2}{*}{$\mathrm{CO}$} & $-2,501 *$ & $3,560 *$ & $7,653^{*}$ & $-35,923^{*}$ \\
\hline & $(0,534)$ & $(0,704)$ & $(0,965)$ & $(2,238)$ \\
\hline \multirow{2}{*}{ privada_total } & $13,432^{*}$ & $-9,946^{*}$ & $-17,370^{*}$ & $6,883^{* *}$ \\
\hline & $(1,190)$ & $(1,472)$ & $(1,912)$ & $(2,918)$ \\
\hline \multirow{2}{*}{ local_pública } & $14,682^{*}$ & $-7,653^{*}$ & $4,754^{*}$ & $12,742^{*}$ \\
\hline & $(0,648)$ & $(0,676)$ & $(1,012)$ & $(1,051)$ \\
\hline \multirow{2}{*}{ c } & $27,475^{*}$ & 0,464 & $-0,668$ & $39,565^{*}$ \\
\hline & $(1,572)$ & $(1,841)$ & $(2,457)$ & $(3,709)$ \\
\hline $\mathrm{R}^{2}$ & 0,6537 & 0,2076 & 0,1786 & 0,6091 \\
\hline $\mathrm{R}^{2}$ Ajustado & 0,6525 & 0,2043 & 0,1754 & 0,6064 \\
\hline Estatística F & 579,033 & 63,772 & 56,473 & 222,218 \\
\hline Probabilidade F & 0,000 & 0,000 & 0,000 & 0,000 \\
\hline Durbin-Watson & 1,970 & 1,989 & 2,011 & 1,834 \\
\hline Jarque-Bera & 1251,133 & 52,285 & 769,806 & 31,524 \\
\hline Probabilidade JB & 0,000 & 0,000 & 0,000 & 0,000 \\
\hline
\end{tabular}

Fonte: Elaboração própria baseada em Snis (2010).

Desvios padrão robustos à heterocedasticidade em parênteses.

Coeficientes significantes a *1\%, a **5\% e a ***10\%. 
A partir dos resultados das estimações constata-se que o sinal do coeficiente para ambos os grupos foi positivo e significante, em relação às regionais públicas, fato que contraria suas funções objetivo. Quando se comparam as empresas privadas e as locais públicas, observa-se uma marginal predominância das últimas nesse índice. Logo, também não se pode afirmar que essa pequena superioridade justifique o objetivo social das locais públicas para provisão de maior cobertura.

No entanto, as privadas apresentam menores índices de perdas de distribuição e faturamento que as locais e regionais públicas, o que pode demonstrar a relativa eficiência desse grupo. Eficiência que pode ser explicada, por exemplo, pela utilização de uma tecnologia mais avançada.

Quanto ao indicador de atendimento total de esgoto, as empresas locais públicas, de acordo com os coeficientes estimados, apresentam um maior resultado ao obtido pelas empresas privadas.

Nesse grupo de indicadores operacionais (água e esgoto), apesar de a função social (fornecer serviços de água e esgoto em regiões pouco atrativas para o investimento privado) dos operadores públicos não se verificar, as empresas privadas apresentam menores índices de perdas no faturamento e na distribuição (tal como esperado pela função objetivo).

É importante ressaltar que, tanto para água quanto para esgoto, os coeficientes das empresas privadas foram significativos quando comparados com as empresas regionais públicas. Logo, é possível sugerir que esteja ocorrendo, no grupo das privadas, o início de um processo de expansão de tais empresas no setor, no sentido de que podem atuar em municípios que ofereçam rentabilidade independente do nível de atendimento que o mesmo apresente. A próxima análise, cujos dados apresentam-se na tabela 5, trata dos indicadores econômicos, financeiros e administrativos.

Tabela 5

Estimação dos indicadores econômicos, financeiros e administrativos

\begin{tabular}{|c|c|c|c|c|}
\hline \multirow[t]{2}{*}{$\begin{array}{l}\mathrm{X}_{\mathrm{i}}=\text { Variáveis } \\
\text { explicativas }\end{array}$} & $\begin{array}{l}Y_{5}=\text { Tarifa média } \\
\text { praticada }\left(\mathrm{R} \$ / \mathrm{m}^{3}\right)\end{array}$ & $\begin{array}{l}Y_{6}=\text { Despesa total } \\
\text { com os serviços por } \\
m^{3} \text { faturado }\left(\mathrm{R} \$ / \mathrm{m}^{3}\right)\end{array}$ & $\begin{array}{c}\mathrm{Y}_{7}=\text { Empregados } \\
\text { próprios por mil } \\
\text { ligações de água } \\
\text { e esgoto } \\
\text { (empreg/mil lig) }\end{array}$ & $\begin{array}{c}Y_{8}=\text { Índice } \\
\text { desempenho } \\
\text { financeiro (\%) }\end{array}$ \\
\hline & \multicolumn{4}{|c|}{ Coeficientes } \\
\hline \multirow{3}{*}{ renda } & 5 & 6 & 7 & 8 \\
\hline & $0,007^{*}$ & 0,002 & $-0,001$ & $0,175^{* *}$ \\
\hline & $(0,002)$ & $(0,002)$ & $(0,003)$ & $(0,081)$ \\
\hline \multirow{2}{*}{ urb } & 0,010 & $-0,939 *$ & $-0,907 *$ & $24,504 *$ \\
\hline & $(0,073)$ & $(0,180)$ & $(0,173)$ & $(3,672)$ \\
\hline
\end{tabular}




\begin{tabular}{|c|c|c|c|c|}
\hline \multirow[t]{2}{*}{$\begin{array}{c}\mathrm{X}_{\mathrm{i}}=\text { Variáveis } \\
\text { explicativas }\end{array}$} & $\begin{array}{l}\mathrm{Y}_{5}=\text { Tarifa média } \\
\text { praticada }\left(\mathrm{R} \$ / \mathrm{m}^{3}\right)\end{array}$ & $\begin{array}{c}\mathrm{Y}_{6}=\text { Despesa total } \\
\text { com os serviços por } \\
\mathrm{m}^{3} \text { faturado }\left(\mathrm{R} \$ / \mathrm{m}^{3}\right)\end{array}$ & $\begin{array}{c}\mathrm{Y}_{7}=\text { Empregados } \\
\text { próprios por mil } \\
\text { ligações de água } \\
\text { e esgoto } \\
\text { (empreg/mil lig) }\end{array}$ & $\begin{array}{c}Y_{8}=\text { Índice } \\
\text { desempenho } \\
\text { financeiro (\%) }\end{array}$ \\
\hline & \multicolumn{4}{|c|}{ Coeficientes } \\
\hline \multirow{3}{*}{ log_pop } & 5 & 6 & 7 & 8 \\
\hline & $0,037 *$ & $-0,029$ & $-0,242^{*}$ & $5,398 *$ \\
\hline & $(0,011)$ & $(0,027)$ & $(0,029)$ & $0,558)$ \\
\hline \multirow{2}{*}{ NO } & 0,098 & $1,342^{*}$ & $3,258 *$ & $-22,829 *$ \\
\hline & $(0,071)$ & $(0,138)$ & $(0,252)$ & $(3,514)$ \\
\hline \multirow{2}{*}{$\mathrm{NE}$} & $-0,179 *$ & $0,397^{*}$ & $-0,016$ & 0,713 \\
\hline & $(0,026)$ & $(0,077)$ & $(0,073)$ & $(1,706)$ \\
\hline \multirow{2}{*}{ SU } & 0,948* & $0,556^{*}$ & $-0,153^{* *}$ & $32,697^{*}$ \\
\hline & $(0,045)$ & $(0,072)$ & $(0,065)$ & $(1,703)$ \\
\hline \multirow{2}{*}{$\mathrm{CO}$} & $0,477^{*}$ & $0,581^{*}$ & $0,637^{*}$ & $9,726^{*}$ \\
\hline & $(0,028)$ & $(0,064)$ & $(0,087)$ & $(2,126)$ \\
\hline \multirow{2}{*}{ privada_total } & $-0,140 * *$ & $-1,108^{*}$ & $-0,409 * * *$ & $24,340^{*}$ \\
\hline & $(0,069)$ & $(0,131)$ & $(0,227)$ & $(3,780)$ \\
\hline \multirow{2}{*}{ local_pública } & $-1,428^{*}$ & $-1,967^{*}$ & 1,090* & 0,702 \\
\hline & $(0,032)$ & $(0,043)$ & $(0,084)$ & $(1,875)$ \\
\hline \multirow{2}{*}{ C } & $1,767^{*}$ & $3,605^{*}$ & $5,261^{*}$ & $17,286^{*}$ \\
\hline & $(0,096)$ & $(0,203)$ & $(0,240)$ & $(4,767)$ \\
\hline $\mathrm{R}^{2}$ & 0,6433 & 0,9622 & 0,7947 & 0,6589 \\
\hline $\mathrm{R}^{2}$ Ajustado & 0,6418 & 0,9620 & 0,7937 & 0,6571 \\
\hline Estatística F & 427,5020 & 4470,8660 & 823,3760 & 377,5940 \\
\hline Probabilidade F & 0,000 & 0,0000 & 0,0000 & 0,0000 \\
\hline Durbin-Watson & 2,0410 & 2,0150 & 2,0330 & 2,0450 \\
\hline Jarque-Bera & 964,195 & 561729,3 & 24014,1 & 12879,15 \\
\hline Probabilidade JB & 0,000 & 0,000 & 0,000 & 0,0000 \\
\hline
\end{tabular}

Fonte: Elaboração própria baseada em Snis (2010).

Desvios padrão robustos à heterocedasticidade em parênteses.

Coeficientes significantes a *1\%, a **5\% e a ${ }^{* * *} 10 \%$. 
Quanto aos resultados dos indicadores acima estimados, as empresas privadas apresentaram menores níveis de tarifa média praticada, em relação às regionais públicas, mas não em relação às locais públicas. ${ }^{6}$ Esse resultado não foi condizente com o estabelecido por sua função objetivo das empresas privadas uma vez que, tanto pelo fato de atuarem em regiões mais prósperas quanto por necessitarem cobrir seus custos e/ou obter retorno de seus investimentos, era esperada a aplicação de tarifas mais elevadas.

O novo marco regulatório do setor de saneamento básico, Lei no 11.445/2007, trouxe perspectivas de resolução de alguns problemas tarifários que prejudicam não só a população de baixa renda, mas todos os consumidores de forma geral. De acordo com a nova Lei, o contrato de concessão firmado entre o titular e o prestador de serviços de saneamento deve deixar indicado, de forma transparente, qual será a definição de taxas e tarifas, as regras de reajustes e revisões, as formas de cobrança e os programas de tarifa social.

Por outro lado, essa situação pode decorrer da maior eficiência relativa das privadas ou ineficiência das regionais: destaca-se uma possível tendência de que a ineficiência dos operadores públicos nos índices de produtividade e de maiores perdas de faturamento e distribuição possa estar relacionada aos problemas de gestão, ao sistema de incentivos e à baixa capacidade de investimento das mesmas.

No que diz respeito aos indicadores restantes desse grupo (de produtividade e desempenho financeiro), as empresas privadas apresentaram melhor desempenho: em relação ao número de empregados próprios por ligações de água e esgoto e maior índice de desempenho financeiro. Porém, em relação à despesa total por $\mathrm{m}^{3}$ faturado, as empresas locais públicas se destacaram quando comparadas com as empresas privadas, apesar de ambas apresentarem coeficientes negativos e significantes.

A indicação de que as empresas privadas geram mais receita relativamente às despesas totais talvez possa ser atribuída ao menor número de empregados próprios por ligações de água e esgoto, uma vez que tais empresas tendem a ser mais produtivas e eficientes, relativamente às regionais públicas.

Por fim, seguem os resultados, na tabela 6, referentes ao grupo dos indicadores de investimento e qualidade.

\footnotetext{
${ }^{6}$ A interpretação do coeficiente mostra que o fato de a empresa prestadora do serviço, no município em questão, ser privada gera uma queda na tarifa de $\mathrm{R} \$ 0,14$ ante uma queda de $\mathrm{R} \$ 1,42$, caso a empresa fosse local pública (em comparação com as empresas regionais e microrregionais públicas).
} 
Tabela 6

Estimação dos indicadores de investimento e qualidade

\begin{tabular}{|c|c|c|c|c|c|c|}
\hline $\begin{array}{c}\mathrm{X}_{\mathrm{i}}=\text { Variáveis } \\
\text { explicativas }\end{array}$ & $\begin{array}{c}\mathrm{Y}_{9}= \\
\text { Investimento } \\
\text { total por ligação } \\
\text { de água e } \\
\text { esgoto }(\mathrm{R} \$ / \mathrm{lig})\end{array}$ & $\begin{array}{c}\mathrm{Y}_{10}= \\
\text { Investimento } \\
\text { total por } \\
\text { habitante } \\
(\mathrm{R} \$ / \mathrm{hab})\end{array}$ & $\begin{array}{c}Y_{11}=\text { Invest. } \\
\text { realizados } \\
\text { com recursos } \\
\text { onerosos } \\
(\%)\end{array}$ & $\begin{array}{c}Y_{12}=\text { Invest. } \\
\text { realizados } \\
\text { com recursos } \\
\text { não onerosos } \\
(\%)\end{array}$ & $\begin{array}{l}\mathrm{Y}_{13}=\text { Invest. } \\
\text { realizados } \\
\text { com recursos } \\
\text { próprios (\%) }\end{array}$ & $\begin{array}{c}\mathrm{Y}_{14}= \\
\text { Indicador de } \\
\text { qualidade } \\
(\%)\end{array}$ \\
\hline & \multicolumn{6}{|c|}{ Coeficientes } \\
\hline \multirow{3}{*}{ renda } & 9 & 10 & 11 & 12 & 13 & 14 \\
\hline & 0,166 & 0,044 & $-0,0002$ & 0,001 & $-0,001$ & $-0,0001^{* *}$ \\
\hline & $(0,335)$ & $(0,070)$ & $(0,0003)$ & $(0,001)$ & $(0,001)$ & $(0,0001)$ \\
\hline \multirow{2}{*}{ urb } & $-39,559 *$ & $18,838^{*}$ & $-0,029$ & $-0,009$ & 0,045 & $-0,028^{*}$ \\
\hline & $(15,718)$ & $(3,210)$ & $(0,022)$ & $(0,022)$ & $(0,033)$ & $(0,009)$ \\
\hline \multirow{2}{*}{ log_pop } & $22,586^{*}$ & $5,995^{*}$ & $0,038^{*}$ & $0,035^{*}$ & $-0,071^{*}$ & 0,001 \\
\hline & $(2,373)$ & $(0,674)$ & $(0,004)$ & $(0,004)$ & $(0,006)$ & $(0,001)$ \\
\hline \multirow{2}{*}{ NO } & $-10,740$ & $-19,479 *$ & 0,041 & $0,038 *$ & $-0,073$ & 0,015 \\
\hline & $(14,455)$ & $(2,355)$ & $(0,031)$ & $(0,015)$ & $(0,038)$ & $(0,012)$ \\
\hline \multirow{2}{*}{ NE } & $-47,819^{*}$ & $-20,732 *$ & $-0,047^{*}$ & $0,083^{*}$ & $-0,040 * *$ & $0,023^{*}$ \\
\hline & $(8,827)$ & $(2,090)$ & $(0,012)$ & $(0,012)$ & $(0,017)$ & $(0,004)$ \\
\hline \multirow{2}{*}{ SU } & $-17,496 * *$ & $-10,648^{*}$ & $-0,067 *$ & 0,001 & $0,070^{*}$ & $0,015^{*}$ \\
\hline & $(7,410)$ & $(1,918)$ & $(0,010)$ & $(0,009)$ & $(0,013)$ & $(0,004)$ \\
\hline \multirow{2}{*}{$\mathrm{CO}$} & $-1,637$ & $-5,817^{*}$ & $-0,058^{*}$ & $0,082^{* *}$ & $-0,024$ & 0,006 \\
\hline & $(8,778)$ & $(2,860)$ & $(0,011)$ & $(0,014)$ & $(0,018)$ & $(0,004)$ \\
\hline \multirow{2}{*}{ privada_total } & $-13,828$ & 3,143 & $-0,085^{*}$ & $-0,052^{*}$ & $0,133^{*}$ & $-0,013^{* *}$ \\
\hline & $(11,636)$ & $(2,929)$ & $(0,028)$ & $(0,013)$ & $(0,033)$ & $(0,005)$ \\
\hline \multirow{2}{*}{ local_pública } & $-38,378^{*}$ & $-9,895^{*}$ & $-0,065^{*}$ & 0,011 & $0,038^{* *}$ & $0,009 * *$ \\
\hline & $(5,388)$ & $(1,492)$ & $(0,008)$ & $(0,011)$ & $(0,015)$ & $(0,003)$ \\
\hline \multirow{2}{*}{ c } & $-95,971^{*}$ & $-38,486^{*}$ & $-0,225^{*}$ & $-0,302^{*}$ & $1,499 *$ & $0,021^{* *}$ \\
\hline & $(22,465)$ & $(6,342)$ & $(0,036)$ & $(0,038)$ & $(0,049)$ & $(0,008)$ \\
\hline$R^{2}$ & 0,3795 & 0,5693 & 0,1546 & 0,1342 & 0,1253 & 0,5197 \\
\hline $\mathrm{R}^{2}$ Ajustado & 0,3766 & 0,5674 & 0,1498 & 0,1289 & 0,1204 & 0,5115 \\
\hline Estatística F & 132,1370 & 300,4510 & 32,3140 & 25,7190 & 25,4550 & 63,6050 \\
\hline Probabilidade F & 0,000 & 0,0000 & 0,0000 & 0,0000 & 0,0000 & 0,0000 \\
\hline Durbin-Watson & 1,9970 & 1,9790 & 1,9270 & 2,1630 & 1,9940 & 1,9119 \\
\hline Jarque-Bera & 365293,70 & 365109,10 & 12760,20 & 15771,50 & 2114,17 & 6445,0090 \\
\hline Probabilidade JB & 0,000 & 0,0000 & 0,0000 & 0,0000 & 0,0000 & 0,0000 \\
\hline
\end{tabular}

Fonte: Elaboração própria da autora baseada em SNIS (2010).

Desvios padrão robustos à heterocedasticidade em parênteses.

Coeficientes significantes a *1\%, a **5\% e a ***10\%. 
Os resultados apontam que, no ano de 2010, tanto as empresas privadas quanto as empresas locais públicas apresentaram investimentos inferiores, em comparação ao nível de investimento realizado pelas empresas regionais públicas.

Os resultados podem demonstrar uma política de redirecionamento de investimentos, iniciada em 2007, pelo Programa de Aceleração do Crescimento (PAC). Mesmo que grande parte das empresas públicas esteja endividada, os valores encontrados podem indicar o êxito de algumas delas na captação de tais recursos. É importante destacar que, a despeito desse resultado, existe um considerável nível de recursos do PAC disponíveis e até mesmo contratados, mas que não estão em vias de realização seja porque as obras estão atrasadas, paralisadas ou não iniciadas, ou pelo fato de que as empresas de direito público (locais ou regionais) não conseguem ter acesso a tais recursos. Isso ocorre devido ao estabelecimento de limites de endividamento aos quais estão submetidas ou ainda por dificuldades relacionadas à elaboração e execução dos projetos.

Quanto aos investimentos com recursos onerosos, esse montante caiu para as empresas privadas ante um aumento de investimento com recursos próprios. Esse resultado pode indicar maior rentabilidade das mesmas ou pode ter se dado em função da conjuntura econômica desfavorável, que levou à retração dos investimentos totais e à maior dificuldade de obtenção de recursos no mercado financeiro.

Deve-se destacar uma série de dificuldades para avaliar o comportamento da variável investimento. No caso das empresas privadas, o investimento pode ser fortemente condicionado pela conjuntura econômica; assim, o resultado das estimativas pode ser reflexo da própria crise internacional iniciada em 2008. Já no caso dos provedores públicos, o investimento pode ser fortemente condicionado por variáveis de natureza política: ano eleitoral, coincidência partidária entre governos locais regionais, locais e federal, entre outros aspectos. Assim, os resultados obtidos para a variável investimento devem ser avaliados com bastante cautela.

Contrariamente ao que era esperado pela função objetivo, o resultado do indicador de qualidade mostra que o trade-off entre custo e qualidade, por ora, pode não ser enfrentado pelos operadores privados. De acordo com a interpretação dessa estimativa, quanto menor o resultado desse indicador, melhor. Dado que esse grupo apresentou um coeficiente negativo, ocorre uma diminuição do indicador de qualidade em relação ao grupo das regionais públicas, ao passo que o coeficiente das locais públicas aumenta o mesmo.

É importante observar que esse resultado pode não ser uma questão de incentivo, mas de definição contratual para controle e monitoramento do cumprimento de diversas metas pelas mesmas. De qualquer forma, a qualidade da água é essencial quando se trata do fornecimento de serviços de saneamento básico.

A despeito dos resultados favoráveis, em vários indicadores apresentados nessa seção para o grupo das empresas privadas, é importante ressaltar que para evitar as preocupações acerca da participação da iniciativa privada no setor, discutidas anteriormente, é imprescindível a atuação do marco regulatório: sem a garantia do poder público de oferecer regulação e planejamento, as vantagens da associação entre diferentes tipos de provedores podem se tornar perversas. 


\section{Considerações finais}

O presente artigo teve o objetivo de verificar se existem diferenças significativas no desempenho de provedores públicos e privados de saneamento básico em relação a um conjunto de indicadores: de atendimento, operacionais, financeiros, de investimento, qualidade, entre outros. Tentou-se observar se essas diferenças poderiam estar associadas a diferentes incentivos específicos de cada grupo.

Os resultados desse estudo mostram que não existe um tipo de provedor que apresente melhor desempenho no conjunto dos indicadores analisados. Quando se compara separadamente, os dois grupos de empresas com o grupo base, as regionais públicas, verifica-se que ambos apresentaram resultados satisfatórios em vários indicadores.

Em relação às empresas privadas, os resultados obtidos confirmaram os sinais esperados das funções objetivo na maior parte dos indicadores. Ou seja, em comparação com as regionais públicas, esperava-se coeficiente positivo para o indicador de desempenho financeiro e coeficientes negativos para os indicadores de perdas na distribuição e no faturamento, despesa com os serviços e empregados próprios por ligações de água e esgoto. Por outro lado, não se esperava coeficiente negativo para o indicador de tarifa média praticada e de qualidade e nem coeficiente positivo para os indicadores de atendimento de água e esgoto.

Vale destacar que as empresas locais públicas obtiveram desempenho favorável em relação às regionais públicas em vários indicadores: atendimento de água e esgoto, perdas na distribuição, despesa com os serviços e tarifa média praticada. Os resultados que não foram satisfatórios referem-se aos indicadores de perdas no faturamento, empregados próprios por ligações de água e esgoto e desempenho financeiro (o coeficiente desse último foi positivo, mas estatisticamente não significante).

No entanto, quando a comparação é feita entre empresas privadas e locais públicas, não existem evidências fortes do predomínio de uma delas em relação à outra. Apenas o indicador de desempenho financeiro e perdas no faturamento, mais favorável às empresas privadas, e o indicador de atendimento de esgoto, mais favorável às locais públicas, podem trazer alguma evidência nesse sentido.

Portanto, é possível afirmar que, apesar da diferença das metodologias utilizadas, os resultados encontrados nesse estudo se assemelham àqueles obtidos pelos outros trabalhos que tratam do tema elencados nesse estudo na terceira seção.

A superação dos problemas do setor de saneamento exige a elevação do nível de investimentos que, por sua vez, deverá requerer diversas modalidades de provisão e gestão. Os provedores públicos devem buscar ganhos de eficiência, ampliação da geração de excedentes e flexibilização de regras de acesso a recursos de terceiros. Por outro lado, deve haver maior participação do setor privado, por meio de parcerias com o setor público e atuação exclusiva em setores que sejam altamente atrativos e/ou naqueles em que o setor público apresente histórico de atrasos e retrocessos.

Os indicadores de acesso do setor de saneamento básico brasileiro mostram que as metas do setor estão longe de serem cumpridas e, portanto, novos estudos que investiguem o 
desempenho dos diversos grupos de prestadores e as motivações aos quais estão submetidos é de suma importância para o desenho de uma política que considere novas soluções para o desafio de universalizar os serviços no país.

\section{Referências}

ABDIB. Associação Brasileira da Infraestrutura e Indústrias de Base. Saneamento básico: investimentos crescem e doenças caem. Análise infraestrutura, ano V, n. 20, jul. 2010. Disponível em: $<$ www.abdib.org.br/arquivos_analise_infraestrutura/an\%C3\%A1lise\%20infraestrutura\%2020. pdf $>$. Acesso em: 5 jul. 2011.

BANDEIRA DE MELLO, Celso A. Curso de direito administrativo. 25. ed. São Paulo: Malheiros, 2008.

BEL, Germà; FAGEDA, Xavier; WARNER, Mildred E. Is private production of public services cheaper than public production? A meta-regression analysis of solid waste and water services. Journal of Policy Analysis and Management, v. 29, n. 3, p. 553-577, Summer 2010. Disponível em: <http:// onlinelibrary.wiley.com/doi/10.1002/pam.20509/pdf>. Acesso em: 2 jul. 2012.

BRASIL. Lei no 8.987, de 13 de fevereiro de 1995. Dispõe sobre o regime de concessão e permissão da prestação de serviços públicos previsto no art. 175 da Constituição Federal, e dá outras providências. Diário [da] República Federativa do Brasil, Brasília, 14 fev. 1995. Seção 1, p. 1917.

BRASIL. Lei no 11.079, de 30 de dezembro de 2004. Dispõe sobre licitação e contratação de parceria público-privada no âmbito da administração pública. Diário [da] República Federativa do Brasil, Brasília, 31 dez. 2004. Seção 1, p. 6.

BRASIL. Lei no 11.445 , de 5 de janeiro de 2007. Estabelece diretrizes nacionais para o saneamento básico; altera as Leis no 6.766, de 19 de dezembro de 1979, 8.036, de 11 de maio de 1990, 8.666, de 21 de junho de 1993, 8.987, de 13 de fevereiro de 1995 e revoga a Lei no 6.528, de 11 de maio de 1978; e dá outras providências. Diário [da] República Federativa do Brasil, Brasília, 8 jan. 2007. Seção 1, p. 3.

CABRAL, Sandro; LAZZARINI, Sergio G.; AZEVEDO, Paulo F. Private operation with public supervision: evidence of hybrid modes of governance in prisons. Social Science Research Network, set. 2007. Disponível em: < http://papers.ssrn.com/sol3/papers.cfm?abstract_id=1017801>. Acesso em: 13 fev. 2007.

CRAIN, Mark W.; ZARDKOOHI, Asghar. A test of the property-rights theory of the firm: water utilities in the United States. Journal of Law and Economics, v. 21, n. 2, p. 395-408, 1978.

ESTACHE, Antonio; KOUASSI, Eugene. Sector organization, governance, and the inefficiency of African water utilities. World Bank Policy Research Working Paper Series 2890, Sept. 2002. Disponível em: <http://rru.worldbank.org/Documents/PaperLinks/1453.pdf>. Acesso em: 3 jul. 2012. 
ESTACHE, Antonio; ROSSI, Martín A. Comparing the performance of public and private water companies in the Asia and Pacific region: what a stochastic costs frontier shows. World Bank Policy Research Working Paper Series 2152, doi: 10.156/1813-9450-2152, 1999.

ESTACHE, Antonio; ROSSI, Martín A. How different is the efficiency of public and private water companies in Asia? World Bank Economic Review, v. 16, n. 1, p. 139-148, 2002.

FARIA, Ricardo C.; MOREIRA, Tito B. S.; SOUZA, Geraldo da S. Public versus private water utilities: empirical evidence for Brazilian companies. Economics Bulletin, 6 Feb. 2005. Disponível em: <www. accessecon.com/pubs/eb/2005/volume8/EB-05H00001A.pdf.>. Acesso em: 12 jul. 2012.

FEIGENBAUM, Susan; TEEPLES, Ronald. Public versus private water delivery: a hedonic cost approach. Review of Economics and Statistics, v. 65, p. 672-678, 1983.

FERNANDOIS, Raquel A. Fomento de la eficiencia de las empresas estatales de água potable y saneamiento. Serie recursos naturales e infraestructura, Santiago de Chile, n. 141, mar. 2009. p. 8-9.

GALIANI, Sebastian; GERTLER, Paul; SCHARGRODSKY, Ernesto. Water for life: the Impact of the Privatization of Water Services on Child Mortality. Journal of Political Economy, v. 113, n. 1, p. 27-28, 2005.

GALVÃO JUNIOR, Alceu de C. et al. Marcos regulatórios estaduais em saneamento básico no Brasil. Revista de Administração Pública, Rio de Janeiro, v. 43, n. 1, p. 207-227, jan./fev. 2009.

GALVÃO JUNIOR, Alceu de C.; MONTEIRO, Mario A. P. Análise de contratos de concessão para a prestação de serviços de água e esgoto no Brasil. Revista de Engenharia Sanitária e Ambiental, v. 11, n. 4, p. 353-361, 2006.

KIRKPATRICK, Colin; PARKER, David; ZHANG, Yin-Fang. State versus private sector provision of water services in Africa. World Bank Economic Review, v. 20, p. 143-163, 2004.

MINISTÉRIO DO PLANEJAMENTO E ORÇAMENTO/SEPURB IPEA. Diagnóstico do setor de saneamento: estudo econômico e financeiro. Série modernização do setor de saneamento/PMSS, Brasília, n. 7, p. 1-250, 1995.

MINISTÉRIO DO PLANEJAMENTO E ORÇAMENTO/SEPURB IPEA. PNAD. Pesquisa Nacional de Amostras e Domicílios. Síntese de Indicadores 2009. Brasília, IBGE, 2010.

MORAES, Luiz R. S. et al. Análise situacional do deficit em saneamento básico: caderno temático no 2. In: REZENDE, S. C. (Org.). Cadernos temáticos. Brasília: Ministério das Cidades, 2011. (Panorama do Saneamento Básico no Brasil, v. 2). No prelo.

MOREIRA, Terezinha. A hora e a vez do saneamento. Revista do BNDES, Rio de Janeiro, n. 10, p. 12, dez. 1998.

OHIRA, Thelma H.; TUROLLA, Frederico A. Gestão, economia e regulação do setor de saneamento básico. In: CONGRESSO DA SOBER, XLIII, 2005, Ribeirão Preto, Anais Instituições, Eficiência, Gestão e Contratos no Sistema Agroindustrial. Pôster. Disponível em: <www.sober.org.br/palestra/2/667. pdf >. Acesso em: 16 out. 2008. 
PARLATORE, Antônio C. Privatização do setor de saneamento no Brasil. In: BNDES. A privatização no Brasil: o caso das utilidades públicas. Rio de Janeiro, 2000. Disponível em: <www.bndes.gov. br/SiteBNDES/bndes/bndes_pt/Institucional/Publicacoes/Consulta_Expressa/Setor/Privatizacao/200002_7.html>.

PNAD. Pesquisa nacional de amostras e domicílios. Síntese de Indicadores 2009. Brasília: IBGE, 2010.

SEROA DA MOTTA, Ronaldo. As opções de marco regulatório de saneamento no Brasil. Plenarium, Brasília, n. 3, p. 100-116, set. 2006.

SEROA DA MOTTA, Ronaldo; MOREIRA, Ajax R. Efficiency and regulation in the sanitation sector in Brazil. Texto para Discussão 1059. Rio de Janeiro: Ipea, 2004.

SNIS. Sistema Nacional de Informação de Saneamento. Diagnósticos dos serviços de água e esgoto 2010. Brasília: Ministério das Cidades, 2010.

TONETO JUNIOR, Rudinei; SAIANI, Carlos C. S. Restrições à expansão dos investimentos no saneamento básico brasileiro. Revista Econômica do Nordeste, Fortaleza, v. 37, n. 4, p. 572-591, out./dez. 2006.

TUROLLA, Frederico A.; OHIRA, Thelma H.; LIMA, Maria F. F. Aspectos econômicos da normatização dos serviços de água e esgoto. In: GALVÃO JUNIOR, Alceu de Castro A. C.; XIMENES, M. M. A. F. (Org.). Regulação: normatização da prestação de serviços de água e esgoto. Fortaleza: Pouchain Ramos, 2008. v. 1, p. 145-160.

Juliana Souza Scriptore é doutoranda em teoria econômica pela Faculdade de Economia, Administração e Contabilidade, Universidade de São Paulo (FEA-USP) e professora assistente do Bacharelado Interdisciplinar em Ciência e Economia da Universidade Federal de Alfenas, Campus Varginha (Unifal-MG). E-mail: juliana.scriptore@unifal-mg.edu.br.

Rudinei Toneto Júnior é livre-docente pela USP, doutor em economia pela Faculdade de Economia, Administração e Contabilidade (FEA-USP) e professor titular do departamento de Economia da Faculdade de Economia, Administração e Contabilidade de Ribeirão Preto (FEA-RP-USP). E-mail: rtoneto@usp.br. 